Bird, T. D., Nemens, E. J. \& Kukull, W. A. (1993) Conjugal Alzheimer's disease: is there an increased risk in offspring? Annals of Neurology, 34, 396-399.

Blansjaar, B. A., Thomassen, R. \& van Schaick, H.W. (2000) Prevalence of dementia in centenarians. International Journal of Geriatric Psychiatry, I5, 219-225.

Farrer, L. A., Myers, R. H., Cupples, L. A., et al (1990) Transmission and age-at-onset patterns in familial Alzheimer's disease: evidence for heterogeneity. Neurology, 40, 395-403.

Gao, S., Hendrie, H. C., Hall, K. S., et al (1998) The relationships between age, sex, and the incidence of dementia and Alzheimer's disease: a meta-analysis. Archives of General Psychiatry, 55, 809-8I5.

Jorm, A. F. \& Jolley, D. (1998) The incidence of dementia: a meta-analysis. Neurology, 5I, 728-733.

Snowdon, D. A., Greiner, L. H., Mortimer, J. A., et a (1997) Brain infarction and the clinical expression of Alzheimer's disease: the Nun Study. Journal of the American Medical Association, 277, 8I3-8I7.

M. Liddell University of Wales College of Medicine, Division of Psychological Medicine, Academic Unit, Monmouth House, Heath Park, Cardiff CFI4 4XN, UK

S. Lovestone Institute of Psychiatry, London, UK M. Owen University of Wales College of Medicine, Cardiff, UK

\section{Treatment for Alzheimer's disease in people with learning disabilities: NICE guidance}

In January 2001 the National Institute for Clinical Excellence (NICE) published Guidance on the Use of Donepezil, Rivastigmine and Galantamine for the Treatment of Alzheimer's Disease. The guidance indicates that the drugs should be made available within the National Health Service to people with mild to moderate Alzheimer's disease whose minimental state examination (MMSE) score is above 12 points. The Institute's guidance does not mention the use of anti-dementia drugs in people with learning disabilities and Alzheimer's disease. Studies have shown that the prevalence of Alzheimer's disease in those with learning disabilities is higher than in the normal population (Patel et al, 1993). This is likely to increase in the future because of the rising life expectancy of people with learning disabilities (Zigman et al, 1997). In Down's syndrome, approximately $40 \%$ develop dementia of Alzheimer type by the age of 60 (Holland et al, 1998).

It is known that clinical evidence for the effectiveness of various psychiatric treatments in the learning disability population is scanty and specialists rely on evidence from the normal population. In this situation, a specialist in the psychiatry of learning disability might consider following the NICE guidance in treating dementia in the people under his or her care. However, there is a major problem, as NICE guidance suggests that treatment should be monitored by MMSE score but the MMSE cannot be used reliably in people with learning disabilities (Deb \& Braganza, 1999). This means that NICE guidance on the use of antidementia drugs is not applicable to people with learning disabilities. This is likely to discourage specialists from prescribing treatment for some patients with a learning disability and Alzheimer's disease who may benefit from it in future. In its guidance, NICE mentioned limitations on the use of the MMSE in people whose Alzheimer's disease is complicated by dysphasia and whose first language is not English, but failed to identify that the MMSE is not standardised for people with learning disabilities who make up $2 \%$ of our population. The fact that this group of people, with a high prevalence of dementia, was completely ignored within the guidance is quite worrying. We appreciate that the guidance from NICE is not prescriptive and does not replace individual judgement; however, complete omission of learning disability could potentially exclude people from receiving beneficial treatment.

Deb, S. \& Braganza, J. (1999) Comparison of rating scales for the diagnosis of dementia in adults with Down's syndrome. Journal of Intellectual Disability Research, 43, 400-408.

Holland, A. J., Hon, J., Huppert, F. A., et al (1998) Population-based study of prevalence and presentation of dementia in adults with Down's syndrome. British journal of Psychiatry, I72, 493-498.

National Institute for Clinical Excellence (200I) Guidance for the Use of Donepezil, Rivastigmine and Galantamine for the Treatment of Alzheimer's Disease. London: NICE.

Patel, P., Goldberg, D. \& Moss, T. (1993) Psychiatric morbidity in older people with moderate and severe learning disability. II: The prevalence study. British Journal of Psychiatry, 163, 481-491.

Zigman, W., Schupf, N., Haveman, M., et al (1997) The epidemiology of Alzheimer's disorder in intellectual disability: results and recommendations from an international conference. Journal of Intellectual Disability Research, 4I, 76-80.

P. Arshad, B. Sridharan, R. Brown

Salford Community Health Care NHS Trust, Meadowbrook, Department of Psychological Medicine, Stott Lane, Salford M6 8HG, UK

\section{Community care for mental disorders in developing countries: a perspective}

Given the limitations of the existing model of community care for mental disorders in developing countries, Jacob (2001) has tried to construct another model and has focused on some of the constituent elements of such a model. Although Jacob insists on a potentially innovative approach to the provision of mental health services in developing countries, the framework within which to take forward the debate regarding community care fails to analyse in depth the sociopolitical and economic contexts in which community care is constructed. Owing to the strong emphasis placed upon discriminatory social and political structures, an analysis of what it is to be mentally ill, and the sociological and psychological implications of this, has largely been ignored.

I agree with Jacob that cooperation between governments and non-governmental organisations (NGOs) in providing community care will help in implementing health care policies. However, by their very nature, NGOs are heterogeneous and vary from large agencies operating in many countries (e.g. Oxfam, Save the Children Fund) to very small organisations operating at village level. Despite the growth of NGO activity in the past decade, there remain questions regarding their effectiveness in achieving their stated objectives (Nyoni, 1987). Evaluation of an NGO's effectiveness can become something of a propaganda exercise, aimed more at impressing donor agencies than at a critical analysis of the NGO's activities. A related issue concerns the mixed accountabilities of NGOs - 'downwards' to their collaborating partners and 'upwards' to their donor agencies. These issues result in difficulties of monitoring and enforcement (Brett, 1993).

We know that the lives of individuals with mental illnesses around the world are usually limited far more by prevailing social, cultural and economic constraints than by their illnesses. If this is the case, then the issues related to community care for people with mental disorders move from those of health to those of human rights. Their lives are hard indeed. Mental health professionals can help to change this state of affairs. Whether the issue is community care in urban London or in rural India, professionals who work on mental 
health issues must extend their perspective beyond the bounds of policies and programmes if they are to help make a meaningful difference in the lives of those they serve.

This does not mean that policies and programmes are not needed - they clearly are. But the tendency to implement readymade models could easily miss the needs of the target groups. Community care programmes have to be tied to broader social and economic policies and programmes. Mental health professionals can contribute their expertise to this process and work in conjunction with these people and their families to strengthen their voices in the arena of human rights.

Brett, E. (1993) Voluntary agencies as developmental organisations: theorizing the problem of efficiency and accountability. Development and Change, 24, 269-303.

Jacob, K. S. (200I) Community care for mental disorders in developing countries. Problems and possible solutions. British Journal of Psychiatry, 178, 296-298.

Nyoni, S. (1987) Indigenous NGOs: liberation, selfreliance, and development. World Development, 15 (suppl.), 5I-56.

B. Saravanan Department of Psychiatry, Christian Medical College, Vellore - 632 002, India

\section{Mental health literacy in developing countries}

The article on mental health literacy by Jorm (2000) was interesting and stimulating and we were encouraged to see reference to the mental health literature in developing countries. However, it portrayed a rather incomplete and negative view of the situation. It has rightly been pointed out that the beliefs in supernatural causes of mental disorders are more widely held and traditional sources of help, such as spiritual healers, are preferred over medical advice for a range of mental health problems in these countries. It was not mentioned, however, that mental health literacy is perhaps part of general literacy. In some developing countries where more than half of the population may be illiterate the dimensions of mental health literacy are totally different from those in Western countries. One corollary of this is that mental health professionals will have to adopt innovative approaches to mental health literacy.

The community mental health programme in Pakistan is an example. With a literacy rate of about $40 \%$, it was not conceivable to adopt the approaches discussed by Jorm (2000). The innovative approaches adopted instead ranged from creating awareness at all levels of health personnel, including primary health care physicians, schoolchildren and teachers in the community, and collaborating with other sectors like traditional faith healers. One interesting attempt in this direction was to create awareness among schoolchildren and their teachers. We believe that the schoolchildren in rural areas are the eyes and ears of the community. In a study evaluating the effect of the school mental health programme it was shown that knowledge, attitudes and superstitions about mental health problems significantly improved in a group of schoolchildren, their friends and neighbours after implementation of the programme, compared with a control group (Rehman et al, 1998). More recently, the work has been extended to the detection of disabilities by children (Gater et al, 1999). This article, which gained the Barker Memorial Award, clearly showed the impact of improved mental health literacy through the strong messenger force of children in the rural community. An interesting impact of improved mental health literacy was its effect on general health indicators such as maternal mortality, infant mortality and the immunisation of children, which were significantly improved following integration of the mental health awareness campaign within primary health care (Maqsood et al, 2001). Similarly, educating the traditional faith healers assisted tremendously in identification and referral of people with mental illnesses for proper psychiatric treatment (Saeed et al, 2000). These are just a few examples of indigenous projects undertaken in the community, which highlight innovative approaches to mental health literacy in a developing country.

Recently, the issue of the role of the World Health Organization in improving mental health literacy in developing countries has been debated (Mubbashar \& Saeed, 2000) and directions for developing cost-effective and sustainable mental health programmes have been outlined.

Gater, R., Saeed, K., Mubbashar, M. H., et al (1999) Detection of disabilities by school children in rural Pakistan. Tropical Doctor, 29, 151-155.

Jorm, A. F. (2000) Mental health literacy. Public knowledge and beliefs about mental disorders. British Journal of Psychiatry, I77, 396-40I.

Maqsood, N., Saeed, K., Mubbashar, M. H., et al (200I) Impact of community based mental health programme on general health care. Lancet, in press.
Mubbashar, M. H. \& Saeed, K. (2000) Round table: setting the $\mathrm{WHO}$ agenda for mental health - WHO can help to combat mental health illiteracy. Bulletin of the World Health Organization, 78, 507-508.

Rehman, A., Mubbashar, M. H., Gater, R., et al (1998) Randomized trial of impact of school mental health programme in rural Rawalpindi, Pakistan. Lancet, 352, $1022-1025$.

Saeed, K., Gater, R., Hussain, A., et al (2000) The prevalence, classification and treatment of mental disorders among attendees of native faith healers in Rural Pakistan. Social Psychiatry and Psychiatric Epidemiology, 35, 480-485.

M. H. Mubbashar Rawalpindi General Hospital Rawalpindi, Pakistan

S. Farooq Postgraduate Medical Institute, Lady Reading Hospital, Peshawar, Pakistan

\section{Handedness and schizophrenia: genetic and environmental factors}

I would like to comment on the conclusions reached by Sommer et al (2001) in their meta-analysis of the literature on cerebral lateralisation and anatomical asymmetry in schizophrenia.

The article opens with the claim that: "Right-handedness, left cerebral dominance for language and normal cerebral asymmetry are considered to be secondary to a dominant allele, the 'right-shift factor" ". It must be kept in mind that this is only a hypothesis and has yet to be proven. Even if the centrality of this gene were demonstrated, the influence of environmental factors would still have to be accounted for. Otherwise, it would be impossible to explain the relatively common discordance for handedness in monozygotic twins: this discordance can only be due to disruption of the intrauterine neurodevelopment in one of the twins caused by the action of environmental factors. This is supported by Steinmetz et al (1995) in which magnetic resonance imaging of twins discordant for handedness showed that this discordance is mirrored by differences in brain lateralisation. Further confirmation of the importance of environmental factors in handedness comes from a Norwegian study by Salvesen et al (1993), in which a cohort of pregnant women were divided in two groups. Half of the mothers had real ultrasound scanning during pregnancy while the others had a sham investigation. When the children were examined after birth there was significant excess of left-handedness only in the group exposed to real ultrasonography. 